\title{
The Meaning and Expression of Wabi-Sabi in Environmental Art Design
}

\author{
Yang Jian ${ }^{1,2 *}$ \\ ${ }^{1}$ Philippine Christian University Center for International Education \\ ${ }^{2}$ Inner Mongolia Honder College of Arts and Sciences \\ *Correspondence: 18889203@qq.com
}

\begin{abstract}
The Wabi-Sabi style has become popular in China's design industry in recent years. It is widely used in the homestay, catering, hotel, and landscape space design. Its popularity is because it combines man, nature, and artificial environment. This paper explores the interaction and symbiosis between environment and human in materialized representation and spiritual connotations in contemporary environmental art design by examining Japanese Wabi-Sabi's origin, concept, expression, and aesthetic philosophy. And it aims to set the proper understanding and application of wabi-sabi among designers. The emphasis on the style of wabi-sabi includes the superficial decoration and pays more attention to "the beauty of nothing" derived from the traditional ordinary definition of beauty. It embodies that the nature and material world is strongly influenced by the humanoriented philosophy based on the aesthetics of recognitions.
\end{abstract}

Keywords: Environmental art design; Wabi-Sabi； Simple; Japanese aesthetics; aesthetic

\section{Introduction}

In environmental art and design, Wabi-Sabi is like a clear stream with its profound and tranquil philosophical connotations and unadorned external expression. This concept inspires the creative inspiration of many design practitioners and arouses their great enthusiasm for the artistic creation of space environments. However, the research on wabi-sabi in China is mainly based on the application of design methods and materials applied in interior design, architectural design, and clothing design. Still, there is little research on the aesthetic philosophy expressed by it. The current design industry tends to be marketing, stylized and commercialized. The selection of design styles primarily caters to the market's taste, focusing on the commercial effect of design forms instead of the humanistic spirit and the social effects of design styles. Designers should reflect on the relationship between design, environment, and people. "Wabi-Sabi" design style is affected by time, geography, philosophy, and religion. It results from a national aesthetic style, which creates a particular aesthetic space environment to express people's recognition of material, space, nature, age over "dull beauty", and people's feedback from nature. Designers should be participants in the market and disseminators of beauty. They should reflect on the relationship between design, aesthetics, environment, and people. The design style of wabi-sabi is influenced by many factors such as specific time, region, philosophy, religion, and so on, and it is an aesthetic style with national individuality, which can create a unique aesthetic space environment. Therefore, designers should have a deep understanding of the philosophical significance of the surface texture of objects, spatial structure, and environmental atmosphere in the design works of this style.

\section{Origin}

Wabi-Sabi is from the Japanese word "侘び", and it is one of the three aesthetic concepts of Classical Japanese literary aesthetics together with "grief over things" and "mystery and lonely" [1]. As early as in the Warring States Period of Japan, Wabi-presibiu, regarded as the tea saint in Japan, created Wabi-Sabi tea. The pursuit of "rough outside, perfect inside" integrates food and spiritual worship into one. Before the Meiji Restoration, Japan was deeply influenced by traditional Chinese culture, including etiquette, writing, art, and religion. Although after the Meiji Restoration, Japan advocated the introduction and learning of western culture in sociology, the unique artistic and aesthetic views of The Japanese nation, which had been deeply influenced by traditional Chinese culture, were still inherited, and maintained. In religion, Zen masters of China and Japan have long had exchanges. In 1192 , Japanese monk Rongxi introduced Indian Buddhism to Japan from China. It integrated Chinese Buddha and Taoist philosophy and built the first Zen temple, which achieved unprecedented development and became the Zen culture with Japanese characteristics, triggered the tea ceremony, and 
established the simple aesthetic concept. Therefore, the origin and evolution of Japanese Zen was much influenced by ancient Chinese philosophy. It can be seen from the architectural style and courtyard design style of Japanese Zen temples that the Japanese tea ceremony is also the product of the combination of Chinese traditional tea culture and Japanese Zen. Wabi-Sabi originated from the Japanese tea ceremony and has become an essential part of the Japanese aesthetic consciousness. It has the meaning of simplicity and quietness. It comes from three Dharma Seals of Buddhism (impermanence, impermanence of dharma, and silence of Nirvana), especially impermanence. The Chinese explained Wabi as "lonely", "cold and quiet", and "pure", which can precisely describe the quiet and peaceful state of mind and attitude required by Zen practice.

\section{The philosophical beauty of Wabi-Sabi}

The core of Wabi-Sabi is Zen, which embodies the negative spirit of Zen in the field of aesthetics. In the Spring and Autumn Period of China, Lao Tzu, the founder of Taoism, for the first time proposed the concept of "Tao" and established the origin of "Tao" -- ontology ${ }^{[2]}$, using "Tao" to explain the origin of all things in the world and the regularity of their movement and change. At the same time, Taoism becomes the principle that human society must follow, and it is the general name of the origin, essence, and law of things. That is why it is said, "tao follows nature". In the forty Chapters of Lao $\mathrm{Zi}$, it is recorded that "all things under heaven are born into being and be born into nothing." The philosophical category of "being" and "nothing" put forward by Laozi gives his simple dialectic thoughts a unique duality. Influenced by Chinese Taoist thought, the Japanese Zen sect combined Buddhist puritanism and Taoist thought into one and transmitted the dialectical philosophy thought of "infinite hidden in nothing" with unique aesthetic cognition and perspective in Japanese Wabi-Sabi aesthetics.

In his book, Wabi-Sabi: The Foundation of Japanese Aesthetics for designers and Living Professionals, Leonard Koren, an American who has lived in Japan for many years, evaluated the aesthetics of Japanese Wabi-Sabi and wrote, "Cut it down to essentials, but do not strip it of its charm, keep it clean and pure but don't strip it of its vitality" [3]. The original intention of Wabi-Sabi is to pursue the origin of things, to keep the state of purity. Even after the baptism of time, it is still possible to explore the plain interior from the undecorated appearance.

In the world of Wabi-Sabi, dried flowers, withered grass, withered leaves, broken cups, and clay POTS are all beautiful. The object's current state results from the dynamic passage of time. The changing "motion" and the "static" of the human mind interweave and circulate in space. It seems that at a particular moment, the object, space and time as the media capture and condense the thought of "Zen", making people closer to it to explore the noumenon of the object and the origin of the object.

\section{The form of Wabi-Sabi}

Wabi-Sabi is the external representation of incomplete, damaged, mottled, withered things, which seems to be the expression of negative, decadent, tired, and other emotions. However, it is just the proof of the existence of things in space and time and the natural nature of things existing in space and dying in time. It can be said that Wabi-Sabi is, in a sense, the retention of space and the retention of time.

In Wabi-Sabi, the idea of "nothing is original" negates all existing forms of beauty. In the early 20th century, Kakuzo Okakura, a Japanese artist and thinker, wrote the Book of Tea in English, which was translated into French, German, Spanish, and other languages. With tea ceremony as the media, this book tells the western world about the traditional beauty of Oriental "art" and "Tao", conveys the inner realm of Oriental "Zen" and the modest and straightforward world view, winning worldwide praise. Wabi Presidium Kakuzo Okakura explains that "Wabi presidium" is Imperfect in appearance and translates it as imperfect, which can be generalized as "imperfect appearance" or "simple and simple appearance" ${ }^{[4]}$, expressing the overwhelming beauty of time passing, mottled appearance and defective objects. See Fig. 1.

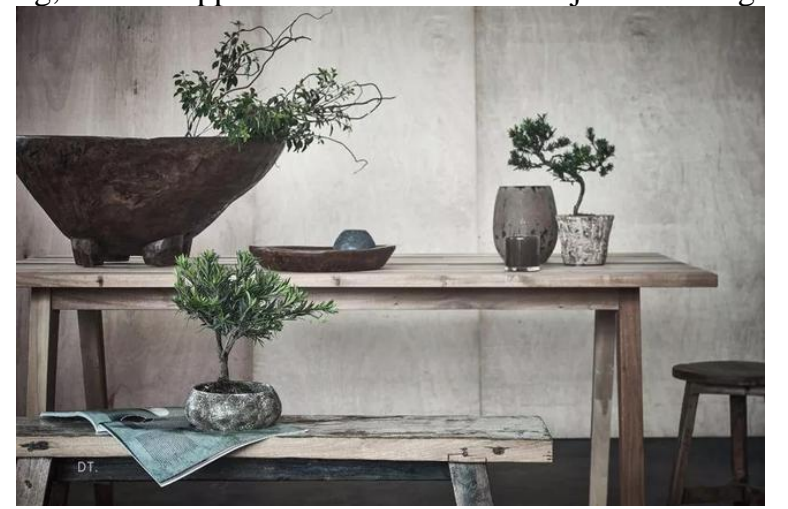

Fig.1 Wabi-Sabi style decoration ${ }^{[5]}$

"Wabi-Sabi" style of a tea set or flower set is perfect, transparent, shining or round. It is mainly made by pottery after piles of mud, mud throwing, hot water, glaze and other multichannel processes in high temperature and forming; as a result, it is usually simple but elegant, natural in colour and shape. Sometimes, unexpected effects might appear due to the temperature, fuel, time, and other uncertain factors. The surface of the vessel or because of the clay mixed with a variety of impurities produced by different shades of colour spots; or enamel nodulation due to different glaze thickness; or uneven colour due to uneven fire. Such a variety of natural, accessible, and easy, and the so-called "imperial kiln" products of the traditional standard beauty formed a sharp contrast. "Wabi-Sabi" style dishes are hand-made, so each one 
is unique. It reveals the unique technique of making the builders mood and aesthetic view, highlighting the workman's creative personality. With a unique exceptional aesthetic, and is also popular in today's market.

Wabi-Sabi seems to be far from the words of riches, luxury, gorgeous and fullness, which are close to showing off and comparing, but closer to the terms of simplicity, simplicity and quietness, which are related to "no competition". The quality and shape of the objects show the "charm" and "god" in Wabi-Sabi, "charm" is its temperament, "god" is its spirit. Most of the utensils used in the Japanese tea ceremony are the clay, bamboo, and rattan. Their functions are for cooking, brewing, placing and storage. In terms of materials, processes, and shapes, traditional handicrafts have been extended and developed to a large extent. Due to the mutual influence of material selection and production technology, the display's shape, color, and texture are different. Japanese ceramics were mostly learned from the Tang and Song dynasties of China. Today, there are still many Chinese tang and Song porcelains in Japan, and they are constantly imitated.

\section{The meaning and context of Wabi-Sabi}

Wabi-Sabi is mainly embodied in temple architecture, dry landscape, and Japanese tea house design.

In traditional Chinese aesthetics, "symmetry" and "balance" are the primary forms, but the Wabi-Sabi style breaks the basic principles of conventional aesthetics and is an asymmetrical aesthetics. Although Japanese architecture and Zen itself were much influenced by Chinese culture, the environment of Wabi-Sabi created by Japanese Zen temples made little use of symmetry and even seemed to be deliberately avoided.

Chinese temples adhere to a strictly symmetrical design in the middle axis in terms of layout. In contrast, Japanese temples are asymmetrical in the left and right sides of the juxta portion of two main halls (such as The Higasihonganji Temple) or the right pagoda and the left hall (such as horiuji Temple). The architectural characteristics spread in the southern and Northern Dynasties of China. The mono-building of Japanese temples followed the style and features of the early Tang Dynasty of China. Still, under the influence of geographical location, climatic conditions, religious belief, and local culture, some architectural components changed regional ethnic characteristics in form, materials and craft. The rest is already localized. (See Fig. 2)

In terms of internal space and material selection, traditional Japanese temple buildings show reverence for nature and worship for trees and fully demonstrate the characteristics of delicate, simple, gentle, and simple Japanese national emotions ${ }^{[7]}$. The building's wooden structure system is generally adopted, and the components are not painted. This structure is simple and natural and keeps its original colour, Columns, beams, rafters, and other exposed wood, the use of simple geometric lines and natural wood texture to sublimate the material's natural beauty. Wood has become the spiritual carrier of temple community architecture and expresses its spiritual connotations by pursuing harmony between architecture and nature.

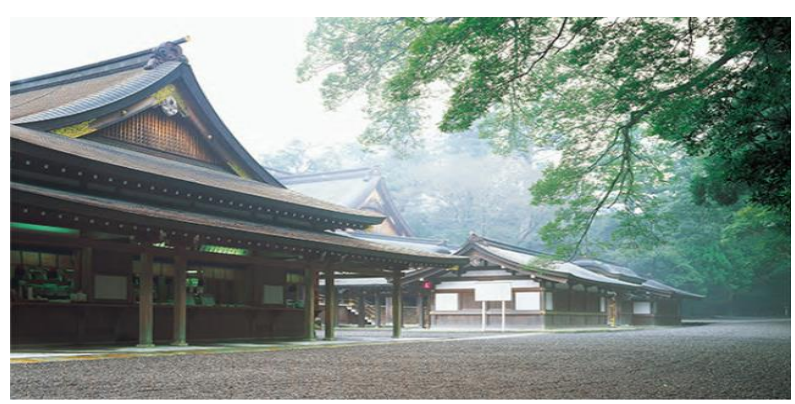

Fig. 2 Ise Shrine, Japan ${ }^{[6]}$

Dry landscape, also known as fake landscape, is a unique element of Japanese gardens and can be the essence and representative of Japanese classical gardens. It is a typical miniature landscape of "seeing big by small", originating in Japan. It is often seen in small, quiet and profound Zen temples ${ }^{[6]}$. In the dry landscape, there is no natural landscape in the scene, but it reflects the grandeur of the natural landscape. White sand and stone-paved for the river flow lake, comb rake texture attached to the dynamic water flow gurgling thought-provoking. The rocks are mountains and islands, standing immovable above the lake and sea. Sand and stone. Water and mountain "movement" and "quietness", the forms of opposites and unity, complement each other well in the landscape art of dry mountains and rivers, presenting the tranquillity, harmony and tolerance of nature in the small and profound Buddhis temple courtyard. There is no majestic architecture, expensive materials, ornamentation, gorgeous colour, or light waves as if everything is nothing, and everything is in it. The Taoist philosophy of "being" and "nothing" is vividly reflected in the dry landscape. (See Fig. 3)

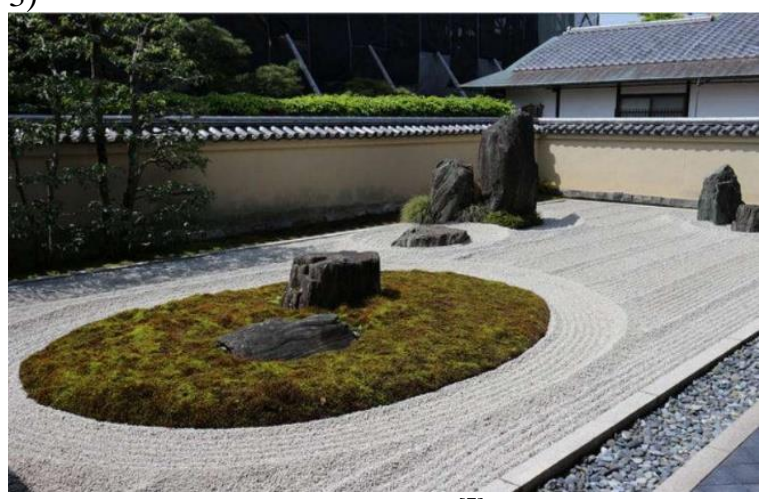

Fig.3 Ryogen-in Temple, Japan ${ }^{[7]}$

Japanese tea ceremony originated in Chaozhou, Guangdong Province, China. Chinese tea culture was introduced to Japan in about the 13th century. In the initial period when the 
custom of tea drinking was introduced to Japan, tea drinking activities were centred on temples and monks. The ideological background of Japanese tea ceremony art is Buddhism, the core of which is Zen, and then evolved into the etiquette of receiving guests and spread widely among the people. Murata Pearl, the "founder of the Japanese tea ceremony", put forward the spirit of " honour, respect, purity, and silence" as the spirit of the tea ceremony. Later, Sen no Rikyū put forward the four words "harmony and respect for purity and silence" as the purpose, which is simple and rich in connotation ${ }^{[8]}$. Among them, "qing $\mathrm{Ji}^{\mathrm{i}}$ is also written "jing ji", a lonely beauty integrated with Zen. This kind of beauty consciousness is embodied in the word Wabi, called "zen tea blindly". In early Japanese history, a tea ceremony "teahouse", also known as "Benxi", "tea mat", is held in the place of tea ceremony; the mats are woven with bamboo and reeds. Teahouse narrow, elegant environment, simple layout; Tea set simple, plain, not gorgeous; in the room, there are hanging scrolls of Zen and precious calligraphy and paintings related to the theme of tea. There are flower arrangement decorations. Flower arrangement varieties vary according to the four seasons. Suppose the uniqueness of the dry landscape lies in the expression of "scenery". In that case, the Japanese tea ceremony teahouse shows the artistic conception of "pursuing and enjoying the luxurious life of aristocrats spiritually" in "implying a noble poverty and exquisite humbleness". ${ }^{[9]}$ (See Fig. 4)

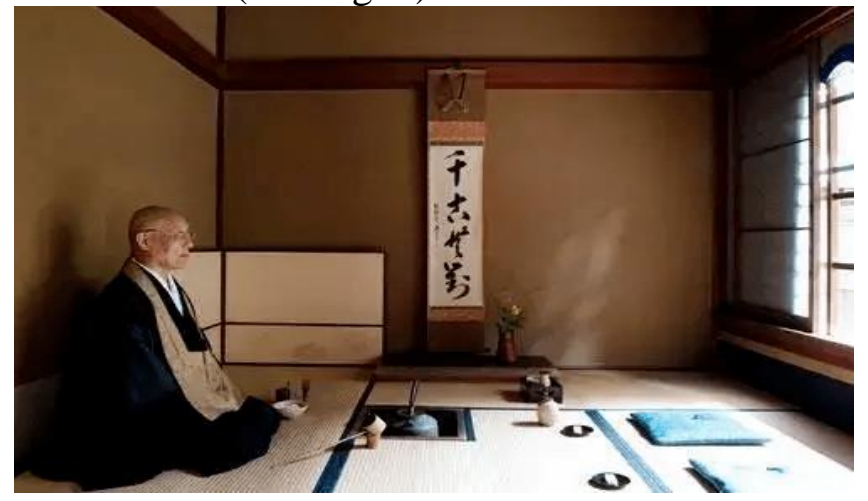

Fig.4, A traditional Japanese tea room ${ }^{[9]}$

\section{Conclusion}

Wabi-Sabi is an essential component of Japanese aesthetics. In aesthetic exploration, it is like "something out of the world", escaping from and existing in the world with the purest and natural appearance. In implicit and symbolic form, it illustrates the mood of selflessness and selflessness, which is "humble but intelligent" compared with the traditional Chinese aesthetics. Wabi-Sabi occupies a place in contemporary environmental art and design in a transcendent form and is even famous for a while. However, original quiet, a simple but elegant "Wabi-Sabi" style changed in the contemporary commercial markets and lost its original meaning and concept ${ }^{[11]}$. The responsibility of modern designers is not only to take more market but also to inherit and develop beauty with a professional attitude. In design, an artist should pursue the spirit of Wabi-Sabi.

The environmental art design is to beautify the physical environment artistically under the premise of complete available functions. The creation of the physical environment is the design technology level, while the spiritual level can resonate with the spatial environment. This article explains the spiritual connotation of "wabi-sabi", which focuses on how to understand and use this style accurately. Understanding the causes, development processes, external performance, and philosophical connotations can make the environment closer to people's spiritual world from the "expression" to "meaning".

\section{References}

[1]. Kempton, B. (2019). Japanese Wabi-Sabi. Beijing United Publishing Company, 1-2

[2]. Zhilong, Tang. (2018). The history of Chinese Philosophy. China Friendship Publishing Company, 65-66

[3]. Koren, L. (2011) Wabi-Sabi: The Foundation of Japanese Aesthetics for Designers and living House. Pedestrian, 54-58

[4]. Okakura, K. (2020) The Book of Tea. Macmillan Collectors, 70-72

[5]. Net ease Suscribtion, China https://www.163.com/dy/article/EHPOF7590520C R77.html

[6]. Young, D. (2019) The Art of Japanese Architecture. Huazhong University of Science and Technology Press, 76.

[7]. Young, D. (2019) The Art of Japanese Architecture. Huazhong University of Science and Technology Press, 75-78

[8]. Mensfield. S. (2019) The Source and Meaning of Dry Landscape. Huazhong University of Science and Technology Press, 51-54-

[9]. Mensfield. S. (2019) The Source and Meaning of Dry Landscape. Huazhong University of Science and Technology Press, 53

[10]. Cha, Wu Long. (2020) Japanese Tea Ceremony Complete Introduction. CITIC Publishing Group,2627

[11]. Is interpretation and generalization of Japanese zen design concept. Packaging engineering,232-236. 